\title{
Involvement of endoplasmic reticulum stress-mediated CHOP (GADD153) induction in the cytotoxicity of 2-aminophenoxazine-3-one in cancer cells
}

\author{
SHOTA MORIYA* , KEISUKE MIYAZAWA* , TOMOHIRO KAWAGUCHI, XIAO-FANG CHE and AKIO TOMODA \\ Department of Biochemistry, Tokyo Medical University, Tokyo, Japan
}

Received April 4, 2011; Accepted May 23, 2011

DOI: $10.3892 /$ ijo.2011.1072

\begin{abstract}
In this study, 2-aminophenoxazine-3-one (Phx-3) exhibited a potent cell growth inhibitory effect with apoptotic features in a dose-dependent manner in various cancer cell lines tested. Comparison of the expression profiles of endoplasmic reticulum (ER) stress-related genes in U266 multiple myeloma cells after treatment with Phx-3 and the ER stress inducers tunicamycin (TNM) and thapsigargin (TPG) indicated that although TNM and TPG potently induced pro-apoptotic transcription factor CHOP (GADD153) within $8 \mathrm{~h}$ of treatment, Phx-3 induced almost no CHOP within $48 \mathrm{~h}$ of treatment in U266 cells. However, murine embryonic fibroblast (MEF) cells and other cancer cell lines (e.g. A549 lung cancer cells and HL-60 acute leukemia cells) exhibited up-regulation of CHOP after treatment with Phx-3. The potency of CHOP induction in response to $\mathrm{Phx}-3$ appeared to be partially correlated with the cytotoxic sensitivity of Phx-3 among various cell lines tested. MEF cells derived from CHOP knockout mice were more resistant to $\mathrm{Phx}-3$ than wild-type MEF cells. Since Phx-3 has been shown to induce activation of $\mathrm{NF}-\kappa \mathrm{B}$, a transcription factor functioning as a repressor of CHOP, we further treated U266 cells with a combination of $\mathrm{Phx}-3$ and $\mathrm{NF}-\kappa \mathrm{B}$ inhibitors (e.g. BAY11-7082 or parthenolide). This enhanced cytotoxicity along with up-modulation of CHOP in U266 cells. These data suggest that ER stress-mediated CHOP induction by $\mathrm{Phx}-3$ is involved in the cytotoxic effect. Regulation of CHOP expression appears to be a potent therapeutic target for cancer treatment.
\end{abstract}

\section{Introduction}

Endoplasmic reticulum (ER) is an organelle found in eukaryotic cells for such key functions as calcium sequestration, protein

Correspondence to: Dr Keisuke Miyazawa, Department of Biochemistry, Tokyo Medical University, 6-1-1 Shinjuku, Shinjuku-ku, Tokyo 160-8402, Japan

E-mail: miyazawa@tokyo-med.ac.jp

*Contributed equally

Key words: phenoxazine, endoplasmic reticulum, ER-stress, CHOP, GADD153 translation, folding and maturation. However, recent reports indicate that ER also has an important role as a sensor for cellular stress. It detects changes in cell homeostasis and responds by triggering signal transduction pathways, known as unfolded protein response (UPR) $(1,2)$. Proteins that fail to adopt the correct conformation are retrotranslocated to the cytosol, and they are ubiquitinated and degraded by the $26 \mathrm{~S}$ proteasome through ER-associated degradation. When the amount of unfolded protein exceeds the capacity of the system, the proteins begin to aggregate in the ER, triggering a programmed death pathway, usually via apoptosis by induction of proapoptotic proteins such as C/EBP homologous protein CHOP (GADD153) $(1,3)$.

Phenoxazine compounds such as 2 -aminophenoxazine-3-one (Phx-3) and 2-amino-4, $4 \alpha$-dihydro-4 $\alpha$-7-demethyl-3Hphenoxazine-3-one $(\mathrm{Phx}-1)$ have been reported to exert an anti-cancer effect against various cancer cells, by inducing cell growth inhibition and apoptotic cell death (4-7). Phx-3 is an oxidative phenoxazine, the essential component of actinomycin D with strong anti-cancer activity. Along with apoptosis induction, $\mathrm{Phx}-3$ induces mitochondrial depolarization and sustained JNK activation in U266 cells (8). The cytotoxic effect of Phx-3 is preceded by a decrease in intracellular $\mathrm{pH}$ in human epidermoid carcinoma cell line KB-3-1 and human chronic myeloid leukemia cell line K562, as well as generating reactive oxygen species in lung adenocarcinoma cell lines (9-11). Simultaneous induction of differentiation and apoptosis by Phx-3 was also reported in malignant melanoma G-361 cells, which produced melanin and induced nuclear chromatin condensation and DNA fragments in response to Phx-3 (12). In vivo experiments demonstrated that $\mathrm{Phx}-3$ prevented pulmonary metastasis of mouse B16 melanoma cells (13). In addition to anti-cancer activity, Phx-3 exhibits various biological activities, including a potent anti-inflammatory effect by suppressing the production of nitric oxide (NO) and prostaglandin E2 (14), as well as immunosuppressive, anti-viral and anti-mycobacterial effects and the elimination of Helicobacter pylori (15-17). All these biological effects suggest the potent therapeutic possibility of Phx-3. Although molecular-based mechanisms for these functions of $\mathrm{Phx}-3$ are becoming evident, the pieces of the puzzle have not yet been clearly put together to explain the all diverse functions of Phx-3.

We recently reported that bortezomib (BZ), the $26 \mathrm{~S}$ proteasome inhibitor approved for treatment of multiple myeloma 
(MM), induces ER stress-mediated cell death along with up-modulation of CHOP (18). BZ has been reported to inhibit $\mathrm{NF}-\kappa \mathrm{B}$ activity by inhibiting proteasome-mediated degradation of $\mathrm{I} \kappa \mathrm{B}$, which is a negative regulatory compartment of $\mathrm{NF}-\kappa \mathrm{B}$ in cytoplasm. However, recent reports by us and others revealed that $\mathrm{BZ}$ did not inhibit, but rather activated, a canonical NF- $\kappa$ B pathway along with enhanced phosphorylation and degradation of I $\mathrm{B} \alpha(18,19)$. Therefore, ER stress may be a major cause of death in MM cells after exposure to BZ. Our previous study also revealed that $\mathrm{Phx}-3$ activates a canonical $\mathrm{NF}-\kappa \mathrm{B}$ pathway with the induction of cytotoxicity in A549 lung cancer cells $(11,18)$. In the present study, we further investigated whether Phx-3 treatment induces ER stress including CHOP induction, and how much ER stress is involved in the cytotoxicity of Phx-3 in tumor cells, including MM cells.

\section{Materials and methods}

Reagents. Phx-3 was prepared from the reactions of o-aminophenol with bovine hemoglobin solution, following the methods described by Tomoda et al (20). Phx-3 was dissolved in a mixture of dimethyl sulfoxide (DMSO) and ethyl alcohol (3:1) as a vehicle to make $20 \mathrm{mM}$ solution. BAY11-7082 was purchased from Calbiochem (Darmstadt, Germany), parthenolide and tunicamycin (TNM) were obtained from Sigma-Aldrich (St. Louis, MO), and thapsigargin (TPG) was purchased from Nacalai Tesque (Kyoto, Japan). These reagents were dissolved in DMSO.

Cell lines and culture conditions. For this study, U266 (a multiple myeloma cell line), HL-60 (an acute myeloid leukemia (AML) cell line), A549 (a lung adenocarcinoma cell line), COLO201 (a colon cancer cell line), U251MG (a glioblastoma cell line), a $\mathrm{CHOP}^{-/-} \mathrm{MEF}$ cell line designated CHOP-KO-DR established from a 13.5-day-old $\mathrm{CHOP}^{-/-}$mouse embryo by SV-40 immortalization and a $\mathrm{CHOP}^{+/+} \mathrm{MEF}$ cell line designated DR-wild-type as a control cell line for CHOP-KO-DR were obtained from the American Type Culture Collection (Rockville, MD). Cell lines U266, HL-60 and COLO201 were maintained in continuous culture in RPMI-1640 medium (Gibco, Grand Island, NY) supplemented with 10\% FBS (Gibco) $2 \mathrm{mM}$ L-glutamine, penicillin (100 U/ml), and streptomycin $(100 \mu \mathrm{g} / \mathrm{ml})$ (Gibco). In addition, A549, U251MG and CHOP-KO-DR and DR-wild-type cells were maintained in Dulbecco's modified Eagle's medium (Sigma) supplemented with $10 \% \mathrm{FBS}$, penicillin $(100 \mathrm{U} / \mathrm{ml})$ and streptomycin $(100 \mu \mathrm{g} / \mathrm{ml})$ in a humidified incubator containing $5 \% \mathrm{CO}_{2}$ and $95 \%$ air at $37^{\circ} \mathrm{C}$.

Assessment of viable number of cells among cultured cells. The number of viable cells was assessed by CellTiter Blue, a cell viability assay kit (Promega Co., Madison, WI), with fluorescence measurements at $570 \mathrm{~nm}$ for excitation and $590 \mathrm{~nm}$ for fluorescence emission.

Immunoblotting. Immunoblotting was performed as previously described (18). In short, cells were lysed with RIPA Lysis Buffer (Santa Cruz Biotechnology Inc., Santa Cruz, CA) containing $1 \mathrm{mM}$ PMSF, $0.15 \mathrm{U} / \mathrm{ml}$ aprotinin, $10 \mathrm{mM}$ EDTA, $10 \mathrm{mg} / \mathrm{ml}$ sodium fluoride, and $2 \mathrm{mM}$ sodium orthovanadate.
Cellular proteins were quantified using a DC protein assay kit of Bio-Rad (Richmond, CA). Equal amounts of proteins were loaded onto the gels, separated by SDS-PAGE and transferred onto Immobilon-P membrane (Millipore Corp., Bedford, MA). The membranes were probed with first antibodies (Abs) such as anti-CHOP (GADD153) Ab, anti-GAPDH mAb and anti$\beta$-actin mAb (Santa Cruz Biotechnology). Immunoreactive proteins were detected with horseradish peroxidase-conjugated second Abs and an enhanced chemiluminescence reagent (ECL) (Millipore). Densitometry was performed using a Molecular Imager, ChemiDoc XRS system (Bio-Rad).

Gene expression analysis. Total RNA was isolated from cell pellets using Isogen (Nippon Gene, Tokyo) and genomic DNA was removed using RQ1 RNase-Free DNase (Promega) at $37^{\circ} \mathrm{C}$ for $30 \mathrm{~min}$, followed by extraction with phenol chloroform and ethanol precipitation. Reverse-transcription using a PrimeScript RT Master Mix (Takara Bio Inc., Ohtsu, Japan) was performed according to the manufacturer's instructions. Real-time PCR was performed on $3 \mathrm{ng}$ of cDNA using validated SYBR-green gene expression assays for human and murine ATF6, IRE1, PERK, GRP78, ATF4, CHOP, GADD34 and $B C L-2$ in combination with SYBR Premix Ex Taq II (Takara Bio Inc.). All primers used in this study are listed in Table I. Quantitative real-time PCR was performed in duplicates in a Thermal Cycler Dice real-time system TP800 (Takara Bio, Inc.) with the following conditions: initial cDNA denaturation at $95^{\circ} \mathrm{C}$ for $30 \mathrm{sec}$, followed by 45 cycles of the sequence of denaturation at $95^{\circ} \mathrm{C}$ for $5 \mathrm{sec}$ and simultaneous annealing and extension at $60^{\circ} \mathrm{C}$ for $30 \mathrm{sec}$. The data were analyzed using Thermal Cycler Dice real-time system software (Takara Bio, Inc.), and the comparative $C_{t}$ method $\left(2^{-\Delta \Delta C t}\right)$ was used for relative quantification of gene expression. The data of real-time PCR products were standardized to GAPDH as an internal control. To confirm the specific amplification of target genes, each gene product after real-time PCR was further separated by $1.5 \%$ agarose gel to detect a single band at the theoretical product size, and the dissociation curves were analyzed to detect a single peak.

Statistics. All data are given as the mean \pm SD. Statistical analysis was performed by using Mann-Whitney's U test (twotailed).

\section{Results}

Cell growth inhibition of Phx-3 in various cancer cell lines. $\mathrm{Phx}-3$ exhibited cell growth inhibition in a dose-dependent manner in various cancer cell lines tested and the MEF cell line (Fig. 1). Morphological studies of the cells after treatment with Phx-3 indicated typical features of apoptosis (e.g. chromatin condensation and nuclear fragments), as previously reported (data not shown) $(5,6)$. Although cell growth inhibition was detected in all cell lines, A549 lung adenocarcinoma cells exhibited the most potent growth inhibition in response to Phx-3. U266 multiple myeloma cells were less sensitive to Phx-3 at concentrations of $<10 \mu \mathrm{M}$, whereas MEF cells exhibited more potent cytotoxicity in response to $\mathrm{Phx}-3$.

Profile of ER stress-related gene expression after exposure to $P h x-3$ in U266 cells and MEF cells. We next examined whether 
Table I. Sequence of primers for real-time PCR.

\begin{tabular}{|c|c|c|c|c|c|}
\hline Symbol & Species $^{\mathrm{a}}$ & Accession no. & Forward (5'-3') & Reverse (5'-3') & $\begin{array}{l}\text { Products } \\
\text { size (bp) }\end{array}$ \\
\hline \multirow[t]{2}{*}{ ATF6 } & $\mathrm{h}$ & NM_007348.2 & AAGCCCTGATGGTGCTAACTGAA & CATGTCTATGAACCCATCCTCGAA & 126 \\
\hline & $\mathrm{m}$ & NM_001081304.1 & GGACGAGGTGGTGTCAGAG & GACAGCTCTTCGCTTTGGAC & 61 \\
\hline \multirow[t]{2}{*}{ PERK } & $\mathrm{h}$ & NM_004836.4 & GCTTATGCCAGACACACAGGACA & CTCCATCTGAGTGCTGAATGGATAC & 150 \\
\hline & $\mathrm{m}$ & NM_010121.2 & CCTTGGTTTCATCTAGCCTCA & ATCCAGGGAGGGGATGAT & 68 \\
\hline \multirow[t]{2}{*}{ IRE1 } & $\mathrm{h}$ & NM_001433.3 & CCCGATCGTGAAGCAGTTAGA & CAGAACCACCTTTATAGGTCCTGAA & 122 \\
\hline & $\mathrm{m}$ & NM_023913.2 & TGAAACACCССТTCTTCTGG & ССТCСTTTTCTATTCGGTCACTT & 78 \\
\hline \multirow[t]{2}{*}{ GRP78 } & $\mathrm{h}$ & NM_005347.4 & CCTAGCTGTGTCAGAATCTCCATCC & GTTTCAATGTCACCATCCAAGATCC & 80 \\
\hline & $\mathrm{m}$ & NM_022310.3 & CTCCACGGCTTCCGATAATCA & TCCAGTCAGATCAAATGTACCCAGA & 106 \\
\hline \multirow[t]{2}{*}{ ATF4 } & $\mathrm{h}$ & NM_182810.1 & CTGCCCGTCCCAAACCTTAC & GCCСTCTTCTTCTGGCGGTA & 139 \\
\hline & $\mathrm{m}$ & NM_009716.2 & ATGATGGCTTGGCCAGTG & ССАТTTTCTCСААСАТССААТC & 78 \\
\hline \multirow[t]{2}{*}{ CHOP } & $\mathrm{h}$ & NM_004083.5 & AAATCAGAGCTGGAACCTGAGGA & CCATCTCTGCAGTTGGATCAGTC & 112 \\
\hline & $\mathrm{m}$ & NM_007837.3 & AATAACAGCCGGAACCTGAGGA & CCCAATTTCATCTGAGGACAGGA & 200 \\
\hline \multirow[t]{2}{*}{ GADD34 } & $\mathrm{h}$ & NM_014330.3 & AACCAGCAGTTCCCTTCCTG & TTGCCTCTCGCTCACCATAC & 74 \\
\hline & $\mathrm{m}$ & NM_008654.2 & AGGAGAAGCTGGGTCCCTAC & GGTCACATCTTGGGTCAAGG & 131 \\
\hline \multirow[t]{2}{*}{$B C L-2$} & $\mathrm{~h}$ & NM_000633.2 & TCAGCATGGCTCAAAGTGCAG & GAAACAGATGTCCCTACCAACCAGA & 151 \\
\hline & $\mathrm{m}$ & NM_009741.3 & GTACCTGAACCGGCATCTG & GGGGCCATATAGTTCCACAA & 76 \\
\hline \multirow[t]{2}{*}{$G A P D H$} & $\mathrm{~h}$ & NM_002046.3 & GCACCGTCAAGGCTGAGAAC & TGGTGAAGACGCCAGTGGA & 138 \\
\hline & $\mathrm{m}$ & NM_008084.2 & TGTGTCCGTCGTGGATCTGA & TTGCTGTTGAAGTCGCAGGAG & 150 \\
\hline
\end{tabular}

${ }^{\mathrm{a} h}$, human; m, mouse.

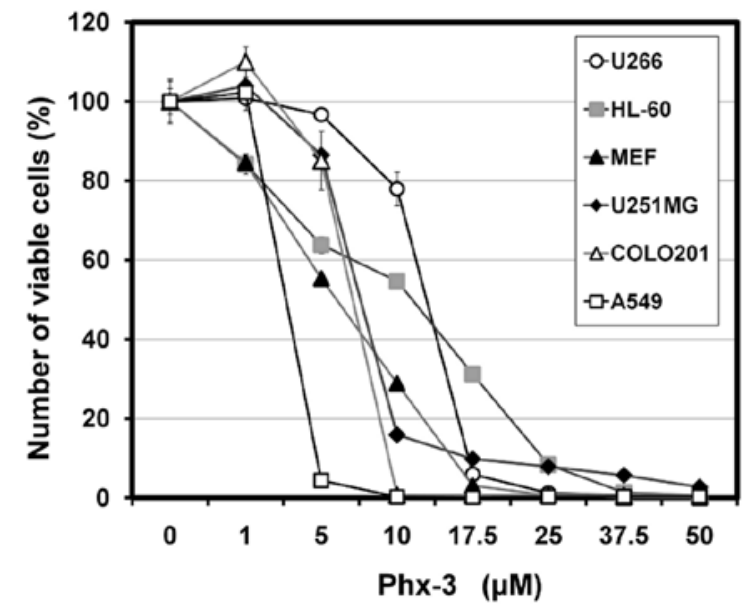

Figure 1. Cell growth inhibition after treatment with $\mathrm{Phx}-3$ in various cancer cell lines. Cells (U266, HL-60, MEF, U251MG, COLO201 and A549) were treated with $\mathrm{Phx}-3$ at various concentrations for $48 \mathrm{~h}$. The viable cell number was assessed by CellTiter Blue as described in Materials and methods.

ER stress-related genes are induced after treatment with Phx-3. First, we chose U266 cells, because our previous report demonstrated that ER stress was induced after treatment with BZ and other ER stress inducers, such as TNM and TPG (18). As indicated in Table II, a series of ER stress-related genes were induced after treatment with TNM and TPG. While dramatically increased expressions of GRP78 and CHOP were observed within $8 \mathrm{~h}$ of with either TNM or TPG, induction of these genes resulted in minimal response after treatment with

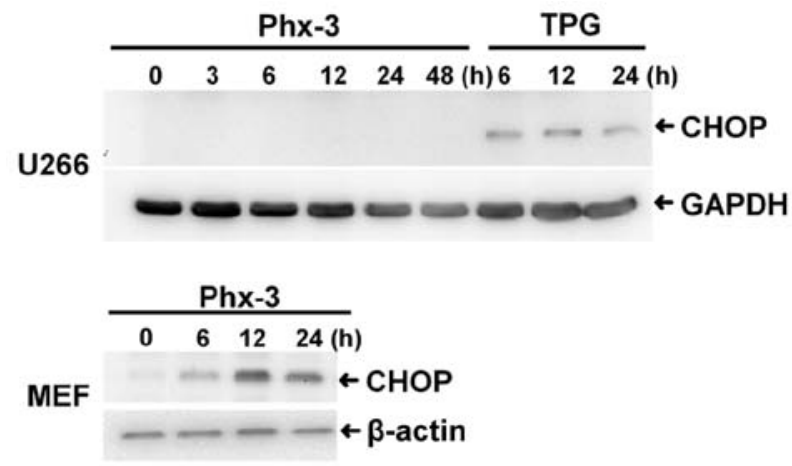

Figure 2. CHOP induction after treatment with Phx-3 and TPG in U266 cells and MEF cells. After treatment with either Phx-3 (10 $\mu \mathrm{M})$ or TPG $(300 \mathrm{nM})$ for various lengths of time, cellular proteins were lysed, separated by $11.25 \%$ SDS-PAGE, and immunoblotted with anti-CHOP Ab. Immunoblotting with either anti-GAPDH mAb or anti- $\beta$-actin $\mathrm{mAb}$ was performed as an internal control.

Phx-3. Immunoblotting with anti-CHOP Ab also demonstrated that TPG induced CHOP within $6 \mathrm{~h}$ of treatment, whereas Phx-3 showed no detectable CHOP in U266 cells during $48 \mathrm{~h}$ exposure (Fig. 2).

Interestingly, comparison of the gene expression profiles of U266 and MEF cells, indicated that CHOP was strongly induced in MEF cells after treatment with $\mathrm{Phx}-3$ (Table II, Fig. 3). This result indicates that MEF cells are more sensitive than U266 cells to ER stress induction by $\mathrm{Phx}-3$. However, although CHOP was strongly induced, GRP78 was not induced by Phx-3 as much in MEF cells as by TNM or TPG treatment 
Table II. Gene expression profiles after exposure to $\mathrm{Phx}-3$ and other ER stress inducers in U266 cells and MEF cells.

\section{A. U266 cells}

Fold change \pm SD

\begin{tabular}{llrrr} 
Symbol & Tx & $8 \mathrm{~h}$ & $24 \mathrm{~h}$ & $48 \mathrm{~h}$ \\
\cline { 3 - 5 } ATF6 & Phx-3 & $0.78 \pm 0.05$ & $0.76 \pm 0.02$ & $0.66 \pm 0.02$ \\
& TNM & $0.71 \pm 0.03$ & $1.39 \pm 0.08$ & $1.79 \pm 0.31$ \\
& TPG & $1.49 \pm 0.01$ & $1.06 \pm 0.09$ & $0.45 \pm 0.01$ \\
PERK & Phx-3 & $0.97 \pm 0.08$ & $0.69 \pm 0.04$ & $0.52 \pm 0.04$ \\
& TNM & $1.81 \pm 0.12$ & $2.48 \pm 0.05$ & $1.91 \pm 0.05$ \\
& TPG & $4.14 \pm 0.30$ & $1.34 \pm 0.08$ & $0.78 \pm 0.03$ \\
IRE1 & Phx-3 & $0.97 \pm 0.06$ & $1.29 \pm 0.06$ & $1.41 \pm 0.03$ \\
& TNM & $0.95 \pm 0.02$ & $1.60 \pm 0.15$ & $1.60 \pm 0.21$ \\
& TPG & $2.27 \pm 0.15$ & $2.03 \pm 0.02$ & $1.94 \pm 0.06$ \\
GRP78 & Phx-3 & $1.65 \pm 0.18$ & $1.21 \pm 0.11$ & $1.11 \pm 0.03$ \\
& TNM & $\mathbf{1 1 . 5 5} \pm 0.47$ & $\mathbf{2 9 . 3 4} \pm 1.14$ & $\mathbf{2 0 . 6 1} \pm 0.56$ \\
& TPG & $\mathbf{3 3 . 2 4} \pm 1.84$ & $\mathbf{1 7 . 6 9} \pm 1.29$ & $\mathbf{1 2 . 0 1} \pm 0.46$ \\
ATF4 & Phx-3 & $2.91 \pm 0.21$ & $1.64 \pm 0.03$ & $1.60 \pm 0.05$ \\
& TNM & $1.42 \pm 0.05$ & $1.79 \pm 0.04$ & $1.37 \pm 0.06$ \\
& TPG & $2.61 \pm 0.05$ & $1.95 \pm 0.01$ & $1.05 \pm 0.05$ \\
CHOP & Phx-3 & $4.31 \pm 0.22$ & $3.30 \pm 0.99$ & $2.40 \pm 0.06$ \\
& TNM & $\mathbf{3 8 . 8 5} \pm 3.32$ & $\mathbf{3 4 . 1 8} \pm 1.21$ & $\mathbf{2 6 . 1 7} \pm 2.29$ \\
& TPG & $\mathbf{5 0 . 0 4} \pm 6.42$ & $\mathbf{2 7 . 4 7} \pm 1.46$ & $\mathbf{2 2 . 7 1} \pm 0.76$ \\
GADD34 & Phx-3 & $2.96 \pm 0.25$ & $3.06 \pm 0.25$ & $2.04 \pm 0.09$ \\
& TNM & $2.45 \pm 0.19$ & $1.63 \pm 0.05$ & $1.24 \pm 0.01$ \\
& TPG & $2.73 \pm 0.01$ & $1.78 \pm 0.03$ & $1.50 \pm 0.09$ \\
BCL-2 & Phx-3 & $0.47 \pm 0.08$ & $0.51 \pm 0.07$ & $0.12 \pm 0.08$ \\
& TNM & $0.09 \pm 0.03$ & $0.75 \pm 0.03$ & $1.77 \pm 0.17$ \\
& TPG & $0.54 \pm 0.09$ & $0.97 \pm 0.06$ & $1.04 \pm 0.15$
\end{tabular}

B. MEF cells

\begin{tabular}{llrrr}
\hline Atf6 & Phx-3 & $2.71 \pm 0.23$ & $2.24 \pm 0.08$ & $2.68 \pm 0.15$ \\
& TNM & $\mathbf{8 . 4 6} \pm 0.11$ & $4.14 \pm 0.47$ & $4.69 \pm 0.27$ \\
& TPG & $\mathbf{6 . 8 7} \pm 0.34$ & $\mathbf{5 . 2 9} \pm 0.22$ & $3.64 \pm 0.05$ \\
Perk & Phx-3 & $1.05 \pm 0.08$ & $0.34 \pm 0.08$ & $0.67 \pm 0.04$ \\
& TNM & $4.97 \pm 0.32$ & $2.30 \pm 0.27$ & $3.06 \pm 0.41$ \\
& TPG & $4.56 \pm 0.17$ & $3.16 \pm 0.16$ & $1.97 \pm 0.11$ \\
Irel & Phx-3 & $2.71 \pm 0.21$ & $2.36 \pm 0.06$ & $3.84 \pm 0.29$ \\
& TNM & $3.99 \pm 0.99$ & $2.51 \pm 0.31$ & $2.78 \pm 0.22$ \\
& TPG & $3.62 \pm 0.08$ & $4.29 \pm 0.15$ & $2.82 \pm 0.16$ \\
Grp78 & Phx-3 & $1.95 \pm 0.15$ & $0.90 \pm 0.02$ & $1.01 \pm 0.05$ \\
& TNM & $\mathbf{2 0 . 4 6} \pm 0.27$ & $\mathbf{1 0 . 2 7} \pm 1.16$ & $\mathbf{1 0 . 1 9} \pm 0.79$ \\
& TPG & $\mathbf{1 8 . 6 4} \pm 0.46$ & $\mathbf{1 0 . 1 6} \pm 0.22$ & $\mathbf{6 . 1 3} \pm 0.11$ \\
Atf4 & Phx-3 & $3.38 \pm 0.25$ & $2.54 \pm 0.14$ & $2.24 \pm 0.14$ \\
& TNM & $\mathbf{7 . 2 4} \pm 0.11$ & $4.58 \pm 0.52$ & $3.92 \pm 0.34$ \\
& TPG & $\mathbf{5 . 3 3} \pm 0.17$ & $4.98 \pm 0.14$ & $2.97 \pm 0.05$ \\
Chop & Phx-3 & $\mathbf{1 6 . 5 1} \pm 1.30$ & $\mathbf{1 8 . 5 7} \pm 0.51$ & $\mathbf{3 2 . 9 0} \pm 2.21$ \\
& TNM & $\mathbf{6 2 . 2 5} \pm 3.31$ & $\mathbf{3 7 . 1 4} \pm 4.21$ & $\mathbf{3 5 . 8 8} \pm 2.27$ \\
& TPG & $\mathbf{6 9 . 7 7} \pm 2.55$ & $\mathbf{7 1 . 0 1} \pm 1.42$ & $\mathbf{4 5 . 8 9} \pm 0.88$ \\
Gadd34 & Phx-3 & $\mathbf{9 . 1 9} \pm 0.75$ & $\mathbf{8 . 7 8} \pm 0.41$ & $4.86 \pm 0.28$ \\
& TNM & $\mathbf{1 5 . 0 3} \pm 0.16$ & $\mathbf{5 . 6 6} \pm 0.66$ & $\mathbf{7 . 0 9} \pm 0.35$ \\
& TPG & $\mathbf{1 2 . 2 1} \pm 0.22$ & $\mathbf{1 0 . 4 1} \pm 0.21$ & $\mathbf{6 . 9 2} \pm 0.08$ \\
Bcl-2 & Phx-3 & $0.53 \pm 0.05$ & $0.23 \pm 0.09$ & $0.91 \pm 0.18$ \\
& TNM & $0.69 \pm 0.07$ & $0.52 \pm 0.07$ & $1.04 \pm 0.38$ \\
& TPG & $0.57 \pm 0.03$ & $0.86 \pm 0.14$ & $0.81 \pm 0.03$ \\
\hline
\end{tabular}

TNM, tunicamycin at $1 \mu \mathrm{g} / \mathrm{ml}$; TPG, thapsigargin at $300 \mathrm{nM}$. Bold indicates more than 5-fold increased gene expression, compared with untreated cells.
(Fig. 3). Therefore, ER stress was exactly induced in response to Phx-3 in MEF cells; however, the quality of ER stress appeared to differ between Phx-3 and TNM or TPG (Table II).

Next, we compared the ability to induce CHOP among various cell lines after treatment with Phx-3 and TMN. CHOP induction in response to Phx-3 varied among cell lines (Fig. 4). However, MEF, A549 and HL-60 cells exhibited higher expression levels of CHOP (9- to 18-fold) than U266, COLO201 and U251MG cells (1- to 5.5-fold). Notably, except for COLO201 cells, sensitivity to $\mathrm{Phx}-3$ in cell growth inhibition appears to be correlated in part with CHOP induction (Figs. 1 and 4).

Involvement of CHOP induction for the cytotoxicity of Phx-3. Our previous report suggested that ER stress-mediated CHOP induction was a major cause of cell death after treatment with BZ in U266 cells (18). Since MEF cells were more sensitive to Phx-3 than U266 cells, and CHOP induction appeared to be related to cell growth inhibition by $\mathrm{Phx}-3$ in part (Figs. 1 and 4), we investigated whether CHOP was involved in the cytotoxic effect by Phx-3 using a MEF cell line derived from CHOP knockout mouse embryo (21). Immunoblottings with anti-CHOP $\mathrm{Ab}$ demonstrated that $\mathrm{CHOP}$ was up-modulated after treatment with Phx-3 or TNM in wild-type MEF cells, whereas CHOP was not detectable in CHOP-KO-DR cells (Fig. 5A). As shown in Fig. 5B, CHOP-KO-DR cells derived from a $\mathrm{CHOP}^{-/}$mouse were more resistant to $\mathrm{Phx}-3$ than $\mathrm{CHOP}^{+/+}$wild-type $\mathrm{MEF}$ cells.

Combined treatment with Phx-3 and NF- $\kappa$ B inhibitors enhances the cytotoxic effect in U266 cells. All the data suggested that ER stress-mediated CHOP induction is, at least in part, involved in the cytotoxic effect of Phx-3. Since NF- $\kappa \mathrm{B}$ has been reported to act as a repressor of CHOP (22) and our previous data demonstrated that Phx-3 activates an NF- $\mathrm{BB}$ pathway (11), we further examined whether combined treatment with Phx-3 and NF- $\mathrm{kB}$ inhibitor enhances cytotoxicity, along with up-modulation of CHOP in U266 cells. BAY11-7082, which inhibits phosphorylation of I $\kappa \mathrm{B} \alpha$, and parthenolide, another inhibitor of IкB kinase (IKK) $\alpha$ and IKK $\beta$ (the upstream activators of the NF- $\kappa \mathrm{B}$ pathway), both exhibited some growth inhibition in U266 cells $(23,24)$. It was noteworthy that combined treatment with Phx-3 and either BAY11-7082 or parthenolide resulted in enhanced cytotoxicity, compared with cells treatment with Phx-3, BAY11-7082, or parthenolide alone (Fig. 6A). In addition, combined treatment of U266 cells with Phx-3 and BAY11-7082 resulted in up-regulation of $\mathrm{CHOP}$, compared with the cells treated with Phx-3 or BAY11-7082 alone (Fig. 6B).

\section{Discussion}

A well-known pro-apoptotic component of UPRs is induction of the basic-leucine zipper transcription factor, $\mathrm{CHOP}$, which is regulated by the PERK-ATF4 and ATF6 pathways under ER stress conditions. CHOP represses the expression of anti-apoptotic proteins Bcl-2 and Bnip3, as well as direct transcriptional induction and translocation to the ER membrane of Bim, a proapoptotic BH3-only protein of the Bcl-2 family (25). It has been reported that overexpression of $\mathrm{CHOP}$ is sufficient to induce cell death in response to ER stress (25). Therefore, CHOP is the key molecule for inducing apoptosis during ER stress (26). 

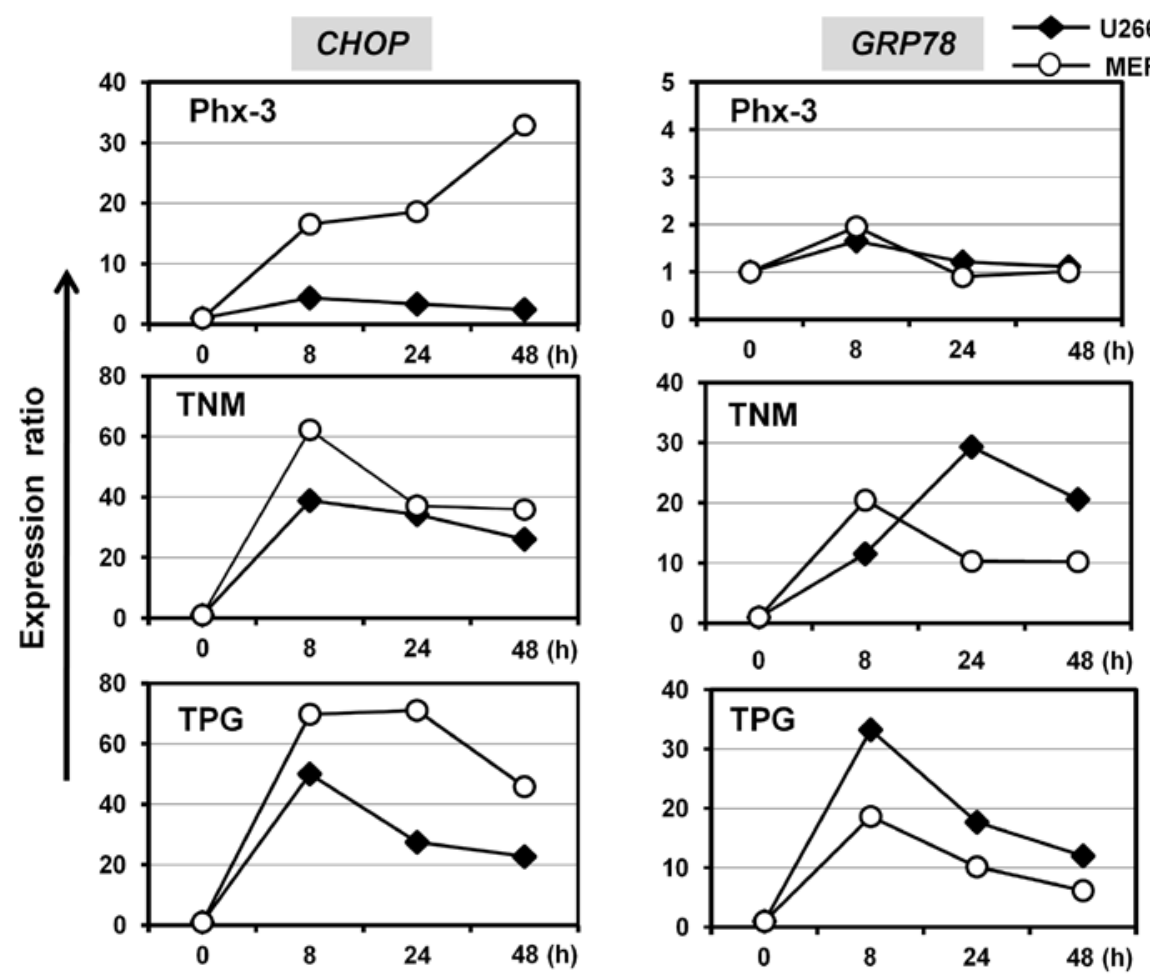

Figure 3. Kinetics of CHOP and GRP78 induction after treatment with Phx-3, TMN, or TPG in U266 and MEF cells. After treatment of U266 cells ( $\bullet$ ) and MEF cells (o) with Phx-3 $(15 \mu \mathrm{M})$, TPG $(300 \mathrm{nM})$ or TNM $(1 \mu \mathrm{g} / \mathrm{ml})$ for various lengths of time, RNA was extracted, and quantitative real-time PCR for CHOP and GRP78 was performed in duplicate, as described in Materials and methods. The data of the real-time PCR products for CHOP and GRP78 were standardized to GAPDH as an internal control. The expression levels of CHOP/GRP78 were compared with those in untreated cells.
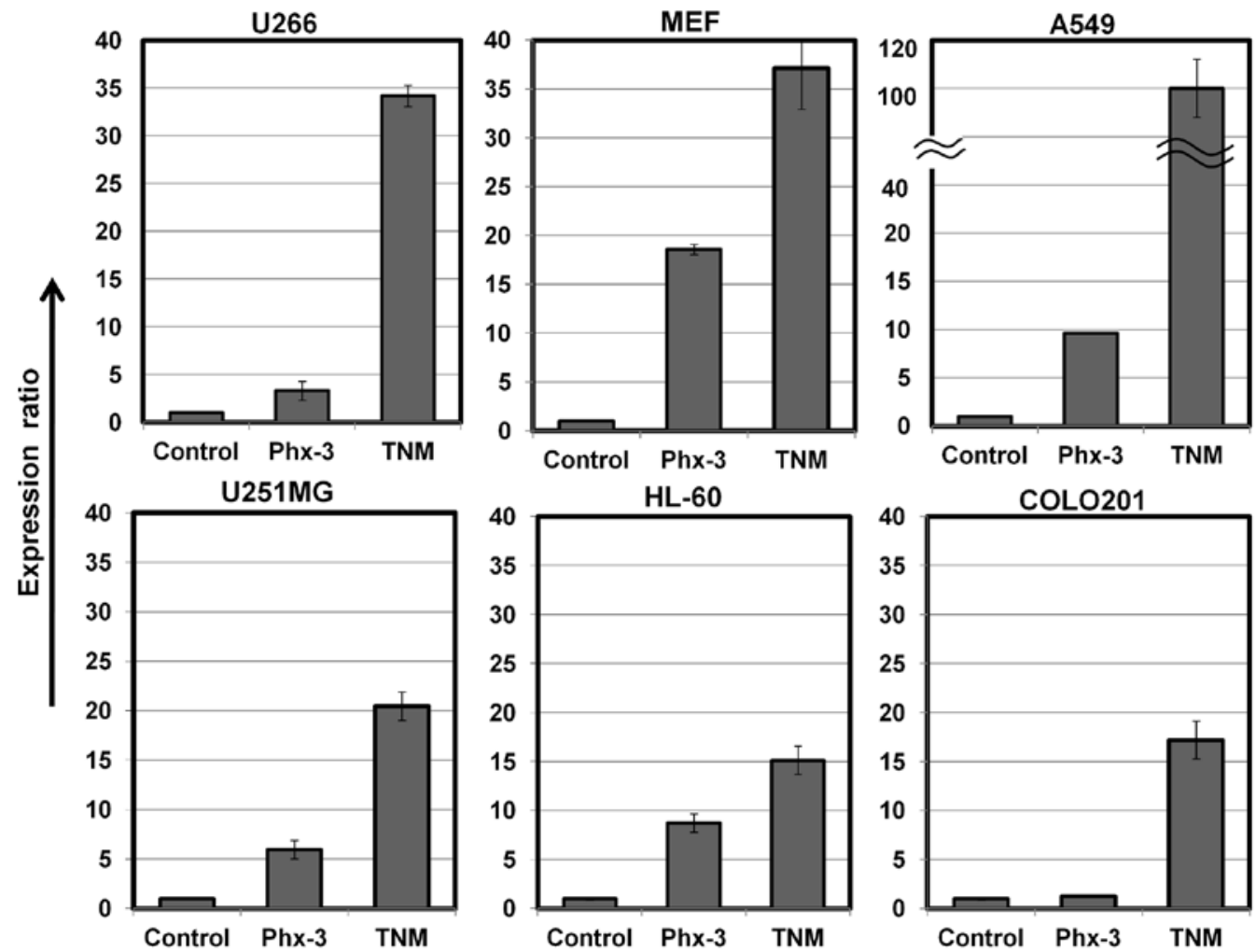

Figure 4. Comparison of CHOP expression after treatment with Phx-3 in various cell lines. After treatment with either Phx-3 or TNM (1 $\mu \mathrm{g} / \mathrm{ml})$ for $14 \mathrm{~h}, \mathrm{RNA}$ was extracted from each cell line, including U266, HL-60, MEF, U251MG, COLO201 and A549. Quantitative real-time PCR for CHOP was performed in duplicate, as described in Materials and methods. The data of the real-time PCR product for CHOP were standardized to GAPDH as an internal control. The expression level of CHOP was compared with that in untreated cells. The concentrations of Phx-3 were determined based on 70\% growth inhibition by Phx-3 for $48 \mathrm{~h}: 5 \mu \mathrm{M}$ for A549, 7.5 $\mu \mathrm{M}$ COLO201, $10 \mu \mathrm{M}$ for MEF and U251MG, $15 \mu \mathrm{M}$ for U266, and $17.5 \mu \mathrm{M}$ for HL-60. 
A

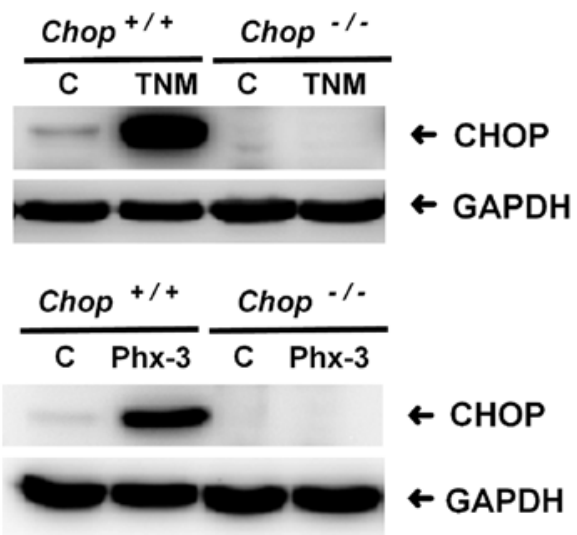

$\mathbf{B}$

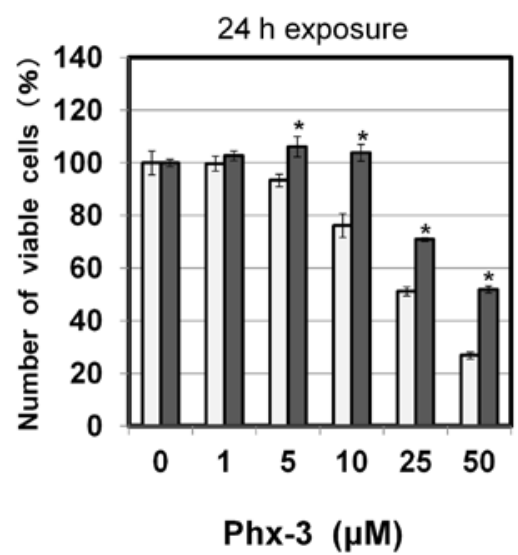

$\square$ Chop $^{+/+}$

$\square$ Chop $\%$

Figure 5. Cell growth inhibition of $\mathrm{CHOP}^{-/} \mathrm{MEF}$ cell line and wild-type MEF cell line after treatment with Phx-3. (A) After treatment with Phx-3 (10 $\left.\mu \mathrm{M}\right)$ or TNM $(1 \mu \mathrm{g} / \mathrm{ml})$ for $12 \mathrm{~h}$, cellar proteins were lysed, separated by $11.25 \%$ SDS-PAGE, and immunoblotted with anti-CHOP Ab. Immunoblotting with antiGAPDH mAb was performed as an internal control. (B) $\mathrm{CHOP}^{-/}$MEF cell line and wild-type $\mathrm{CHOP}^{+/+} \mathrm{MEF}$ cell line were cultured in the presence of Phx-3 at various concentrations for 24 and $48 \mathrm{~h}$. The viable cell number was assessed by CellTiter Blue as described in Materials and methods. "p<0.05 vs. wild-type MEF cells.

A

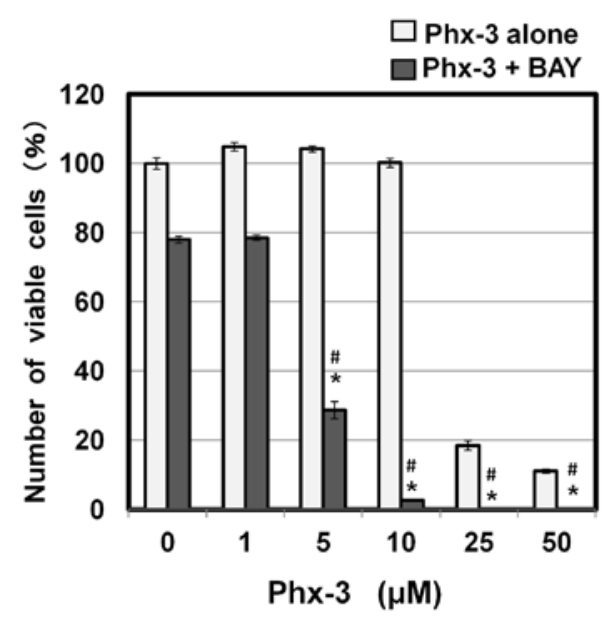

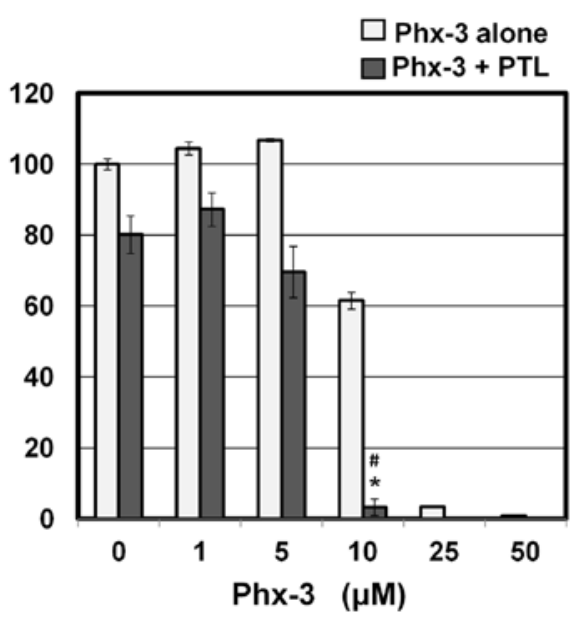

B

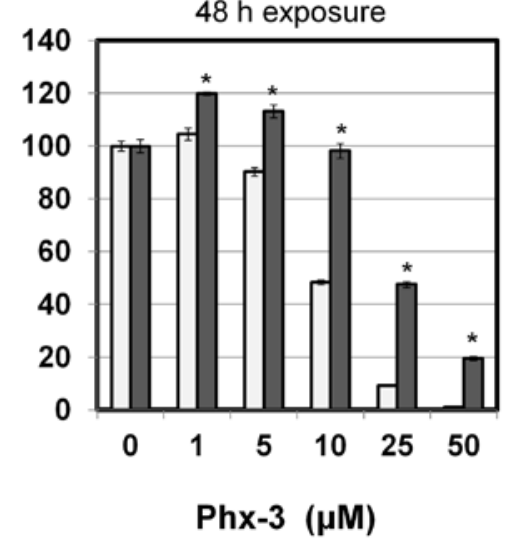

Figure 6. Combined treatment with Phx-3 and NF- $\kappa$ B inhibitors in U266 cells. (A) U266 cells were cultured with Phx-3 at various concentrations and/or either BAY11-7082 (BAY, $15 \mu \mathrm{M})$ or parthenolide (PTL, $5 \mu \mathrm{M})$ for $48 \mathrm{~h}$. The viable cell number was assessed as described in Materials and methods. ${ }^{*}$ p $<0.05 \mathrm{vs}$. Phx-3 alone, ${ }^{\#} \mathrm{p}<0.05$ vs. BAY11-7082 or parthenolide alone. (B) After treatment of U266 cells with Phx-3 (10 $\left.\mu \mathrm{M}\right)$ and/or BAY11-7082 (15 $\left.\mu \mathrm{M}\right)$ for 8,24 and $48 \mathrm{~h}$, RNA was extracted, and quantitative real-time PCR was performed to assess CHOP mRNA expression as described in Materials and methods. The data of the real-time PCR product for CHOP were standardized to GAPDH as an internal control. The expression level of CHOP was compared with that in untreated U266 cells.

In the present study, we demonstrated that Phx-3 induced ER stress and up-regulated CHOP, although the expression levels varied among the cell lines tested. Myeloma cell line U266 indicated lower $\mathrm{CHOP}$ induction in response to $\mathrm{Phx}-3$, whereas MEF cells exhibited higher levels (Fig. 3 and Table II). The extent of CHOP induction in response to $\mathrm{Phx}-3$ in cell lines was partially correlated with sensitivity to cell growth inhibition by $\mathrm{Phx}-3$. In addition, the MEF cell line derived from CHOP knockout mouse was far less sensitive in cytotoxicity to Phx-3 than the wild-type MEF cell line (Fig. 5B). Therefore, all these data suggest that ER stress-mediated CHOP induction was involved in the cytotoxicity of Phx-3.

Interestingly, although GRP78 was strongly induced in response to TNM and TPG, little induction of GRP78 was observed in response to $\mathrm{Phx}-3$ even in MEF cells showing potent up-modulation of CHOP after Phx-3 treatment (Table IIB). GRP78 interacts with the ER luminal domain of three stress sensors (e.g. PERK, IRE1 and ATF6); however, upon accumulation of unfolded proteins, GRP78 dissociates from these molecules, leading to their activation. As a chaperon, GRP78, which has a conserved ATPase domain and a peptide-binding domain, recognizes and binds to proteins with hydrophobic residues in the unfolded regions $(25,26)$. Regarding GRP78 transcription, the GRP promoters contain multiple copies of the ER stress response element (ERSE) (27). TPG, which blocks the ER calcium ATPase pump, thereby depleting the ER calcium store. TNM inhibits protein glycosylation by blocking the first step in the biosynthesis of N-linked oligo- 
saccharides in the ER and Golgi $(28,29)$. ER stress-inducers (e.g. TPG and TNM) have been reported to promote TFII-I, a signal-induced multifunctional transcription factor, to bind to GRP78 promoter and enhance its transcriptional activity (30). Currently, it is unclear how $\mathrm{Phx}-3$ induces ER stress. It has been reported that $\mathrm{Phx}-3$ induced a rapid decrease of intracellular $\mathrm{pH}(\mathrm{pHi})$ associated with the inhibition of $\mathrm{Na}^{+} / \mathrm{H}^{+}$exchanger isoform 1 (NHE1) in the plasma membrane of gastric cancer cell lines $(9,10)$. The reduction of $\mathrm{pHi}$ precedes an apoptotic event in response to $\mathrm{Phx}-3$ and greatly suppresses glycolysis in cancer cells, which may cause ER stress. However, the limited induction of GRP78 by Phx-3 in U266 and MEF cells shown in Table IIB suggests that the quality of signals toward ER stress caused by Phx-3 is different from the quality of those by TPG and TNM. Interestingly, both TMN and TPG, but not Phx-3, potently induce autophagy in various cell lines (personal observation by S.M. and K.M.). Regarding signals from ER stress to autophagy, ATF4, a transcription factor and a component of the PERK pathway, was reported to facilitate autophagy through direct binding to a cyclic AMP response element binding site in the LC3B promoter, following up-regulation of LC3B and autophagy induction in response to sever hypoxia $(3,31)$. Up-regulation of ATF4 by TMN and TPG was indeed more prominent than by Phx-3 in MEF cells (Table IIB). This result may also explain the difference in the quality in ER stress between Phx-3 and the other two agents, although the signals appear to converge to $\mathrm{CHOP}$ for induction of apoptosis.

We previously reported that $\mathrm{Phx}-3$ activates $\mathrm{NF}-\kappa \mathrm{B}$ during the induction of apoptosis (11). To clarify how NF- $\kappa B$ is activated by $\mathrm{Phx}-3$, two pathways for $\mathrm{NF}-\kappa \mathrm{B}$ activation via ER stress were analyzed. In response to ER stress, a serine/threonine kinase PERK phosphorylates the eukaryotic translation initiation factor $(\mathrm{eIF} 2 \alpha)$. This event results in the inhibition of most cap-dependent translation including $\mathrm{I} \kappa \mathrm{B}$, followed by the activation of $N F-\kappa B$ (32). In addition, IRE1 $\alpha / T R A F 2$ can recruit the $\mathrm{I} \kappa \mathrm{B}$ kinase, which mediates the activation of $\mathrm{NF}-\kappa \mathrm{B}$ (33). Therefore, activation of $\mathrm{NF}-\kappa \mathrm{B}$ in response to $\mathrm{Phx}-3$ can be explained by ER stress-mediated pathways. However, $\mathrm{NF}-\kappa \mathrm{B}$ has also been reported to function as a suppressor of $\mathrm{CHOP}$. Previous reports demonstrated that NF- $\kappa \mathrm{B}$ promoted cell survival during ER stress by repressing $\mathrm{CHOP}$ expression via the p65 subunit but not the p50 subunit of NF- $\mathrm{NB}$ (22). This finding was also supported by our data indicating that combined treatment with Phx-3 plus NF- $\mathrm{NB}$ inhibitors further enhanced cytotoxicity, along with up-modulation of $\mathrm{CHOP}$ in U266 cells (Fig. 6). The lower expression level by Phx-3 in U266 cells may be explained by the repressor function of $\mathrm{NF}-\kappa \mathrm{B}$ for CHOP (Fig. 3). Additionally, NF- $\kappa \mathrm{B}$ activation during ER stress may function as a negative feed-back loop for regulating pro-apoptotic signals via $\mathrm{CHOP}$ repression.

All our data suggest that ER stress-mediated CHOP induction is involved in the cytotoxicity of Phx-3. Additionally, regulation of $\mathrm{CHOP}$ induction such as inhibition of $\mathrm{NF}-\kappa \mathrm{B}$ appears to be a potential therapeutic target for cancer treatment.

\section{Acknowledgements}

This study is supported in part by funds from the Private University Strategic Research-Based Support Project (Molecular Information-based Intractable Disease Research Project) from the Ministry of Education, Culture, Sports, Science and Technology of Japan to A.T. and K.M. (2008-2012), and a grant-in-aid for scientific research (C) from the Ministry of Education, Culture, Sports, Science and Technology of Japan to K.M. (no. 22591050).

\section{References}

1. Ron D and Walter P: Signal integration in the endoplasmic reticulum unfolded protein response. Nat Rev Mol Cell Biol 8: 519-529, 2007.

2. Herr I and Debatin K-M: Cellular stress response and apoptosis in cancer therapy. Blood 98: 2603-2613, 2001.

3. Verfaillie T, Salazar M, Velasco G and Agostinis P: Linking ER stress to autophagy: potential implications for cancer therapy. Int $\mathrm{J}$ Cell Biol (In press).

4. Mori H, Honda K, Ishida R, Nohira T and Tomoda A: Antitumor activity of 2-amino-4,4alpha-dihydro-4alpha, 7-dimethyl-3Hphenoxazine-3-one against Meth A tumor transplanted into BALB/c mice. Anticancer Drugs 11: 653-657, 2000.

5. Abe A, Yamane M and Tomoda A: Prevention of growth of human lung carcinoma cells and induction of apoptosis by a novel phenoxazinone, 2-amino-4,4alpha-dihydro- 4alpha,7-dimethyl3H-phenoxazine-3-one. Anticancer Drugs 12: 377-382, 2001.

6. Shirato K, Imaizumi K, Miyazawa K, Takasaki A, Mizuguchi J, Che XF, Akiyama S and Tomoda A: Apoptosis induction preceded by mitochondrial depolarization in multiple myeloma cell line U266 by 2-aminophenoxazine-3-one. Biol Pharm Bull 31: 62-67, 2008.

7. Miyano-Kurosaki N, Ikegami K, Kurosaki K, Endo T, Aoyagi H, Hanami M, Yasumoto J and Tomoda A: Anticancer effects of phenoxazine derivatives revealed by inhibition of cell growth and viability, disregulation of cell cycle, and apoptosis induction in HTLV-1-positive leukemia cells. J Pharmacol Sci 110: 87-97, 2009.

8. Takasaki A, Hanyu H, Iwamoto T, Shirato K, Izumi R, Toyota H, Mizoguchi J, Miyazawa K and Tomoda A: Mitochondrial depolarization and apoptosis associated with sustained activation of c-jun-N-terminal kinase in the human multiple myeloma cell line U26 induced by 2-aminophenoxazine-3-one. Mol Med Rep 2: 199-203, 2009.

9. Che XF, Akiyama S and Tomoda A: Suppression of the proliferation of cancer cell lines, KB-3-1 and K562 cells preceded by a decrease in intracellular $\mathrm{pH}$ caused by phenoxazine derivatives. Oncol Rep 19: 1253-1258, 2008.

10. Nagata H, Che XF, Miyazawa K, Tomoda A, Konishi M, Ubukata $\mathrm{H}$ and Tabuchi T: Rapid decrease of intracellular $\mathrm{pH}$ associated with inhibition of $\mathrm{Na}^{+} / \mathrm{H}^{+}$exchanger precedes apoptotic events in the MNK45 and MNK74 gastric cancer cell lines treated with 2-aminophenoxazine-3-one. Oncol Rep 25: 341-346, 2011.

11. Zheng CL, Che XF, Akiyama S, Miyazawa K and Tomoda A: 2-Aminophenoxazine-3- one induces cellular apoptosis by causing rapid intracellular acidification and generating reactive oxygen species in human lung adenocarcinoma cells. Int J Oncol 36: 641-650, 2010.

12. Shimizu S, Suzuki M, Miyazawa K, Yokoyama T, Ohyashiki K, Miyazaki K, Abe A and Tomoda A: Differentiation and apoptosis in human malignant melanoma G-361 cells induced by 2-aminophenoxazine-3-one. Oncol Rep 14: 41-46, 2005.

13. Miyano-Kurosaki N, Kurosaki K, Hayaashi M, Takaku H, Hayafune M, Shrato K, Kasuga T, Endo T and Tomoda A: 2-Aminophenoxazine-3-one suppresses the growth of mouse malignant melanoma B16 cells transplanted into C57BL/6Cr Slc mice. Biol Pharm Bull 29: 2197-2201, 2006.

14. Shimizu S, Suzuki M, Tomoda A. Arai S, Taguchi H, Hanawa T and Kamiya S: Phenoxazine compounds produced by the reactions with bovine hemoglobin show antimicrobial activity against non-tuberculosis mycobacteria. Tohoku J Exp Med 203: 47-52, 2004.

15. Kohno K, Miyake M, Sano O, Tanaka-Kataoka M, Yamamoto S, Koya-Miyata S, Arai N, Fujii M, Watanabe H, Ushio S, Iwaki K and Fukuda S: Anti-inflammatory and immunomodulatory properties of 2-amino-3H-phenoxazin-3-one. Biol Pharm Bull 31: 1938-1945, 2008

16. Hayashi K, Hayashi T, Miyazawa K and Tomoda A: Phenoxazine derivatives suppress the infections caused by herpes simplex virus type- 1 and herpes simplex virus type- 2 intravaginally inoculated into mice. J Pharmacol Sci 114: 85-91, 2010. 
17. Hanawa T, Osaki T, Manzoku T, Fukuda M, Kawakami H, Tomoda A and Kamiya S: In vitro antibacterial activity of Phx-3 against Helicobacter pylori. Biol Pharm Bull 33: 188-191, 2010.

18. Kawaguchi T, Miyazawa K, Moriya S, Ohtomo T, Che XF, Naito M, Itoh $\mathrm{M}$ and Tomoda $\mathrm{A}$ : Combined treatment with bortezomib plus bafilomycin A1 enhances the cytocidal effect and induces endoplasmic reticulum stress in U266 myeloma cells: crosstalk among proteasome, autophagy-lysosome and ER stress. Int J Oncol 38: 643-654, 2011.

19. Hideshima T, Ikeda H, Chauhan D, Okawa Y, Raje N, Podar K Mitsiades C, Munshi NC, Richardson PG, Carrasco RD and Anderson KC: Bortezomib induces canonical nuclear factorkappaB activation in multiple myeloma cells. Blood 114 1046-1052, 2009.

20. Tomoda A, Arai S, Ishida R, Shimamoto T and Ohyashiki K: An improved method for the rapid preparation of 2-amino-4,4a-dihydro-4a,7-dimethyl-3H-phenoxazine-3-one, a novel antitumor agent. Bioorg Med Chem Lett 11: 1057-1058, 2001.

21. Sok J, Wang XZ, Batchvarova N, Kuroda M, Harding H and Ron D: CHOP-dependent stress-inducible expression of a novel form of carbonic anhydrase VI. Mol Cell Biol 19: 495-504, 1999.

22. Nozaki S, Sledge GW Jr and Nakshatri H: Repression of GADD153/CHOP by NF-kappaB: a possible cellular defense against endoplasmic reticulum stress-induced cell death. Oncogene 20: 2178-2185, 2001.

23. Fabre C, Carvalho G, Tasdemir E, Braun T, Adès L, Grosjean J, Boehrer $S$, Métivier D, Souquère $S$, Pierron $G$, Fenaux $P$ and Kroemer G: NF-kappaB inhibition sensitizes to starvationinduced cell death in high-risk myelodysplastic syndrome and acute myeloid leukemia. Oncogene 26: 4071-4083, 2007.

24. Hassane DC, Sen S, Minhajuddin M, Rossi RM, Corbett CA Balys M, Wei L, Crooks PA, Guzman ML and Jordan CT: Chemical genomic screening reveals synergism between parthenolide and inhibitors of the PI-3 kinase and mTOR pathways. Blood 116: 5983-5990, 2010.

25. Toth A, Nickson P, Mandl A, Bannister ML, Toth K and Erhardt P: Endoplasmic reticulum stress as a novel therapeutic target in heart diseases. Cardiovasc Hematol Disord Drug Targets 7: 205-218, 2007.
26. Oyadomari S and Mori M: Roles of CHOP/GADD153 in endoplasmic reticulum stress. Cell Death Differ 11: 381-389, 2004

27. Sato M, Yao VJ, Arap W and Pasqualini R: GRP78 signaling hub a receptor for targeted tumor therapy. Adv Genet 69: 97-114, 2010.

28. Wong WL, Brostrom MA, Kuznetsov G, Gmitter-Yellen D and Brostrom CO: Inhibition of protein synthesis and early protein processing by thapsigargin in cultured cells. Biochem J 289: 71-79, 1993

29. Wang X, Eno CO, Altman BJ, Zhu Y, Zhao G, Olberding KE, Rathmell JC and Li C: ER stress modulates cellular metabolism. Biochem J (In press).

30. Hong M, Lin MY, Huang JM, Baumeister P, Hakre S, Roy AL and Lee AS: Transcriptional regulation of the Grp78 promoter by endoplasmic reticulum stress: role of TFII-I and its tyrosine phosphorylation. J Biol Chem 280: 16821-16828, 2005.

31. Rzymski T, Milani M, Pike L, Buffa F, Mellor HR, Winchester L, Pires I, Hammond E, Ragoussis I and Harris AL: Regulation of autophagy by ATF4 in response to severe hypoxia. Oncogene 29: 4424-4435, 2010.

32. Schapansky J, Olson K, Van Der Ploeg R and Glazner G: NF-kappaB activated by ER calcium release inhibits Abetamediated expression of CHOP protein: enhancement by AD-linked mutant presenilin 1. Exp Neurol 208: 169-176, 2007.

33. Kaneko M, Niinuma Y and Nomura Y: Activation signal of nuclear factor-kappa $\mathrm{B}$ in response to endoplasmic reticulum stress is transduced via IRE1 and tumor necrosis factor receptorassociated factor 2. Biol Pharm Bull 26: 931-935, 2003.

34. Du S, Hiramatsu N, Hayakawa K, Kasai A, Okamura M, Huang T, Yao J, Takeda M, Araki I, Sawada N, Paton AW, Paton JC and Kitamura M: Suppression of NF-kappaB by cyclosporin a and tacrolimus (FK506) via induction of the C/EBP family: implication for unfolded protein response. J Immunol 182: 7201-7211, 2009. 